\title{
Laparoscopic gastric resections with per oral specimen extraction in the treatment of intramural gastric tumors
}

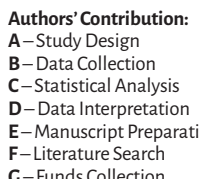

\author{
Maciej Stanek ${ }^{\mathrm{CDEF}}$, Piotr Major ${ }^{\mathrm{BD}}$, Mateusz Wierdak ${ }^{\mathrm{CF}}$, Michał Pędziwiatr ${ }^{\mathrm{BD}}$, Dorota Radkowiak ${ }^{\mathrm{F}}$ \\ Anna Zychowicz ${ }^{F}$, Andrzej Budzyński ${ }^{\mathrm{ABDE}}$ \\ II Katedra Chirurgii Ogólnej, Uniwersytet Jagielloński, Collegium Medicum; Klinika Chirurgii Endoskopowej, Metabolicznej \\ oraz Nowotworów Tkanek Miękkich, Kopernika 21, 31-501 Kraków, Polska
}

ABSTRACT:

Aim: The goal of this paper was to present our experiences and results of treatment of gastric tumors using the per oral specimen extraction (POSE) technique.

Material and methods: A retrospective analysis of a group of patients treated with laparoscopic stomach wedge resection of gastrointestinal stromal tumor (CIST). 50 patients underwent laparoscopy due to the suspicion of CIST. In 12 patients resected material was removed endoscopically per os (POSE). In the remaining 38 subjects it was evacuated through minilaparotomy. Mean age of patients treated using POSE technique was 65.6 years (48-81 years). There were 9 women and 3 men in this group.

Results: Mean time of the POSE procedure was $92.5 \mathrm{~min}$ (40-160 min). Size of removed tumors ranged from $14 \mathrm{~mm}$ to $40 \mathrm{~mm}$ (mean: $25 \mathrm{~mm}$ ). The mean length of hospital stay was 3.2 days ( 2 to 8 days) for patients treated with POSE. One patient $(8.3 \%)$ required longer hospitalization ( 8 days) due to the presence of a fluid collection at the site of gastric suture. This patient was treated conservatively. One patient (8.3\%) was diagnosed with surgical site infection (wound at the navel after an optical trocar). Histopathological examination confirmed radical excision in all of our patients (Ro).

Conclusions: It seems that the POSE technique is the next stage of development of minimally invasive surgery and may constitute a link in evolution of natural orifice transluminal surgery techniques. The removal of the postoperative specimen through the oral cavity is an attractive, effective, and safe method despite its many limitations.

KEYWORDS:

laparoscopy, gastrointestinal stromal tumors, POSE, endoscopy

\section{INTRODUCTION}

Minimally invasive techniques play an increasingly more important role in gastric surgery [1]. Application of laparoscopy in the treatment of gastric tumors has numerous benefits, such as reducing postoperative pain, shortening hospital stay, early patient mobilization, or better esthetic effect [2,3,4]. However, conventional laparoscopic techniques usually require enlarging one of the wounds in order to remove the excised material. It increases the risk of trocar site complications, such as infection or incisional hernia $[5,6]$. In order to reduce that risk, techniques have been developed that enable evacuation of tissue material via natural body orifices [7]. It eliminates the risk of minilaparotomy, thus decreasing the risk of wound-related complications and producing better cosmetic effects [8].

Per oral specimen extraction (POSE) is one of the methods used for removing postoperative specimen. This route is usually reserved for surgery of the upper gastrointestinal tract, particularly the stomach. It involves intraoperative gastroscopy and removal of the specimen using endoscopic tools.

The goal of the paper was to present the experiences and early results of the treatment of stomach tumors using per oral specimen extraction technique. 


\section{METHODS}

We conducted a retrospective analysis of patients who had undergone laparoscopic wedge stomach resection due to a suspicion of a gastrointestinal stromal tumor (GIST).The procedure was performed in patients with submucosal gastric tumors identified based on imaging studies and endoscopic examination, in whom neoplastic process of endothelial origin was excluded.Each patient had undergone gastroscopy in the preoperative period in order to establish location of the lesion, its diameter, and to obtain biopsy specimen for histopathological examination. Contrast computed tomography was performed in all patients to exclude possible metastases and to document tumor location relative to neighboring organs. Early treatment results, such as: procedure duration, number and type of postoperative complications, course and length of hospital stay after the procedure were analysed.

\section{SURGICAL TECHNIQUE}

The initial phase of the laparoscopic per oral specimen extraction (POSE) were condacted in a simmilar manner to conventional laparoscopy. Intraoperative gastroscopy was subsequently performed to confirm exact location of the tumor. After confirming its location, gastric region containing the tumor was freed and dissected.

After the appropriate gastric region had been freed, the lesion was excised with a tissue margin using a harmonic knife. The specimen was placed in a latex coverand subsequently seized with a loop or Dormia Basket. In a next step the endoscope together with the specimen were removed through patient's mouth.The opening in the stomach wall was closed with an absorbable continuous suture. The endoscope was then reintroduced into the stomach in order to review tightness of sutures and to confirm gastric patency. Subsequent stages were no different from a standard laparoscopic procedure. Hemostasis was checked, pneumoperitoneum was deflated and trocar wounds were closed in a typical manner.

\section{MATERIAL}

We analyzed medical records of patients treated with minimally invasive surgery due to a diagnosed submucosal tumor between July 2010 and July 2016. Fifty patients underwent laparoscopy over that period for suspected GIST of the stomach. In 12 patients resected material was removed per os using an endoscope (POSE). In the remaining 38 patients tissue was extracted through minilaprotomy by widening a trocar wound.
A decision to remove the lesion through the oral cavity was made based on tumor size and intraoperative assessment of technical possibilities of extraction.

Mean age of patients treated with POSE was 65.6 years (48-81 years). The group consisted of 9 women and 3 men. In 4 patients (33.3\%) the character of the lesion could be verified preoperatively. In the remaining 8 subjects (66.7\%) the lesion was identified after histopathological examination of excised specimen. None of the patients treated with laparoscopy due to submucosal gastric tumor were preoperatively diagnosed neither with metastases to distant locations nor to regional lymph nodes.

Study group characteristics are presented in Table 1.

\section{RESULTS}

Table 2 presents tumor characteristics, locations, and the extent of resection.

Mean time of POSE procedure was $92.5 \mathrm{~min}$ (40-160 min). Size of the excised tumors ranged from $14 \mathrm{~mm}$ to $40 \mathrm{~mm}$ (mean: $25 \mathrm{~mm}$ ). In four cases per oral removal of the lesion was attempted, but the tumor could not be safely passed through the gastric inlet due to its size (over $4 \mathrm{~cm}$ ). In those cases per oral tumor removal was relinquished and the tumor was evacuated through minilaparotomy via trocar wound. In all patients operated on using POSE method oral fluid administration was commenced on the day of surgery. Ten (91\%) patients tolerated oral fluids well on the first day. Oral diet was tolerated well by 9 (82\%) patients on the second day after surgery. All (100\%) patients were mobilized on the day of the procedure. The mean length of hospital stay among patients treated with POSE technique was 3.2 days ( 2 to 8 days). One patient (8.3) required prolonged hospitalization ( 8 days) due to the presence of a fluid collection at the suture site. That patient was treated conservatively. One patient (8.3\%) was diagnosed with surgical site infection (trocar wound at the navel). No other postoperative complications were noted in the group of patients after per oral specimen extraction procedure.

Histopathological examination confirmed radical excision (R0) in the entire study group of patients.

\section{DISCUSSION}

Gastrointestinal stromal tumors (GIST) are rare [9], but pose a significant clinical problem due to their unpredictable course. The basis of the treatment is the local excision with a 
margin of macroscopically healthy tissues. Unlike malignant tumors of endothelial origin, GIST tumors rarely metastasize to lymph nodes; thus, it does not seem necessary to remove regional lymphatic system [10]. These characteristics suggest that minimally invasive surgical techniques might be particularly useful in the treatment of those types of malignancies.

Since those tumors develop in the deep layers of the gastrointestinal system [11] and are often covered with unchanged mucosa, preoperative evaluation is not easy. Successful histopathological verification requires a biopsy of deep layers of the wall, while collection of tissue samples during standard endoscopy might not yield positive result. In our group of patients treated using POSE technique, preoperative verification of the lesion was successful in $33.3 \%$ of cases. In the remaining cases gastrointestinal stromal tumor was suspected despite the lack of unequivocal confirmation. Therefore, those patients were referred for the local excision of the suspicious lesion and the same treatment as in GIST.

The concept of natural orifice transluminal endoscopic surgery (NOTES) arose together with the development of the minimally invasive surgical techniques [7]. Even though this method has not become fully established in the field of surgery, some of its elements are becoming increasingly popular. The per oral specimen extraction technique is a kind of link between conventional laparoscopy and NOTES. The natural orifice specimen extraction (NOSE) technique is most frequently used in colorectal surgery. It is also used in surgery of the upper gastrointestinal tract (as in the case of above-discussed group).

The POSE method may be used both for the treatment of neoplastic lesions, as well as of other diseases (e.g. sleeve gastrectomy) $[13,14]$. However, despite many advantages it is not without limitations. One of those limiting factors is the size of extracted specimen. Gastric cardia, the narrowest space the specimen needs to pass through, is crucial to the POSE technique. The ability to transfer the specimen without too much resistance determines the safety of this procedure. In our material POSE was attempted in 4 patients, but due to the size of excised tissue the procedure was foregone, as there were concerns regarding its safety. In those cases it was necessary to perform minilaparotomy and specimen were removed in the same manner as in conventional procedures. Therefore, the POSE method appears to be inapplicable to larger tumors (in our material the largest tumor excised through POSE was $4 \mathrm{~cm}$ in diameter). It is worth noting that small tumors, which can be removed through oral cavity, do not usually require extensive minilaparotomy and may be also extracted through a slightly enlarged trocar wound.
Tab. I. Group characteristics

\begin{tabular}{ll} 
Age & 65,6 lat (48-81 lat) \\
\hline Women & 9 chorych (48\%) \\
\hline Men & 3 chorych $(52 \%)$ \\
BMI (Body Mass Index) & $28,1 \mathrm{~kg} / \mathrm{m}^{2}(22,6-38,7)$ \\
\hline
\end{tabular}

Two approaches to gastric resection for GIST have been used at our Department. At the beginning, wedge resections using endoscopic staplers were performed. With time, procedures involving local tumor excision using a harmonic knife with subsequent closing of the stomach wall with continuous sutures became more popular. In the first method it is not possible to remove the specimen through the mouth, as while cutting the specimen away, the stapler closes access to the stomach lumen. Therefore, POSE may be used practically only in cases of tumor excision that do not involve a stapler. There are reports in the available literature of POSE during procedures performed using a stapler, but in such cases application of this technique seems controversial. During the procedure specimen is initially excised with a stapler. At successive stages stomach wall is incised, the specimen is placed in the lumen of gastrointestinal tract and removed through oral cavity. At last, stapler closes the opening in the stomach and a small fragment of gastric wall is removed through a trocar wound [14].

When POSE is used in the treatment of intramural gastric tumors, the procedure differs from the standard laparoscopy only in the way of the removing of the specimen. Currently, endoscopic staplers are no longer used for gastric resections for intramural tumors at our Department due to the fact that application of a stapler requires somewhat more extensive resection compared to local excision and closing of the wall with an absorbable suture. In our opinion, the use of staplers increases the extent of resection and the risk of postoperative gastric stenosis.

One more issue should be noted: POSE requires an additional person in the operating theater - a capable and experienced endoscopist, who will be able to remove the specimen through the oral cavity using endoscopic tools. Additional equipment is also necessary, although in this case basic instrumentation, such as: endoscope, endoscopic loop or Dormia Basket, should suffice.

However, compared to conventional procedures, POSE requires the involvement of more people and additional equipment. The insufficient number of doctors in Poland as well as financial constraints on hospitals may argue against use of this 
Tab. II. Characteristics of submucosal tumors

\begin{tabular}{|c|c|c|c|c|}
\hline No. & TUMOR LOCATION & DIAMETER & TYPE OF PROCEDURE & CHARACTER OF THE LESION \\
\hline 1 & Prepyloric region, posterior wall & $25 \mathrm{~mm}$ & Local tumor excision & GIST \\
\hline 2 & Gastric body, anterior wall & $30 \mathrm{~mm}$ & Local tumor excision & GIST \\
\hline 3 & Gastric body, greater curvature & $38 \mathrm{~mm}$ & Local tumor excision & GIST \\
\hline 4 & Gastric body, greater curvature & $25 \mathrm{~mm}$ & Wedge resection & GIST \\
\hline 5 & Gastric body, anterior wall & $33 \mathrm{~mm}$ & Local tumor excision & GIST \\
\hline 6 & Gastric body, greater curvature & $20 \mathrm{~mm}$ & Wedge resection & GIST \\
\hline 7 & Prepyloric region, greater curvature & $14 \mathrm{~mm}$ & Wedge resection & Ectopic pancreatic tissue \\
\hline 8 & Gastric body, lesser curvature & $25 \mathrm{~mm}$ & Wedge resection & GIST \\
\hline 9 & Prepyloric region, anterior wall & $40 \mathrm{~mm}$ & Local tumor excision & Lipoma \\
\hline 10 & Gastric body, posterior wall & $20 \mathrm{~mm}$ & Local tumor excision & Neuroendocrine tumor \\
\hline 11 & Prepyloric region, greater curvature & $15 \mathrm{~mm}$ & Local tumor excision & Ectopic pancreatic tissue \\
\hline 12 & Prepyloric region, anterior wall & $20 \mathrm{~mm}$ & Local tumor excision & Gastricmucosalprolapsepolyp \\
\hline
\end{tabular}

technique in everyday surgical practice. Another argument raised by the proponents of NOTES is, that it allows avoiding a minilaparotomy, thus reducing the risk of surgical site infection or the developement of incisional hernia [2,3]. In cases of small lesions percutaneous removal of the tumor requires only a small extension of the trocar wound. It seems that slight widening of one of the wounds should not significantly impact the risk of infection. In cases of larger lesions avoiding minilaparotomy seems more significant, but one should remember that extraction through oral cavity might not be technically possible due to a disproportion between the specimen size and the diameter of gastric cardia.

\section{REFERENCES}

1. Barchi L.C., Jacob C.E., Bresciani C.J., Yagi O.K., Mucerino D.R., Lopasso F.P., Mester M., Ribeiro-Júnior U., Dias A.R., Ramos M.F., Cecconello I., Zilberstein B.: Minimally invasive surgery for gastric cancer: Time to change the paradigm. Arq. Bras. Cir. Dig. 2016 Apr.-

2. Jun.;29 (2): 117-120.

3. Adachi Y., Suematsu T., Shiraishi N., Katsuta T., Morimoto A., Kitano S. Akazawa K.: Quality of life after laparoscopy-assisted Billroth I gastrectomy. Ann. Surg. 1999 Jan.;229 (1): 49-54.

4. Kinoshita T., Shibasaki H., Oshiro T., Ooshiro M., Okazumi S., Katoh R. Comparison of laparoscopy-assisted and total laparoscopic Billroth-I gastrectomy for gastric cancer: a report of short-term outcomes. Surg. Endosc. 2011 May; 25 (5): 1395-1401.

5. Pędziwiatr M., Matłok M., Kisialeuski M., Major P., Migaczewski M., Budzyński P., Ochenduszko S., Rembiasz K., Budzyński A.: Enhanced recovery (ERAS) protocol in patients undergoing laparoscopic total gastrectomy. Wideochir. Inne Tech. Małoinwazyjne. 2014 Jun.;9 (2): 252-257.

6. Julliard O., Hauters P., Possoz J., Malvaux P., Landenne J., Gherardi D.: Incisional hernia after single-incision laparoscopic cholecystectomy: incidence and predictive factors. Surg. Endosc. 2016 Feb. 19. [Epub ahead of print]

\section{CONCLUSIONS}

It appears that POSE method is another step in the developement of minimally invasive surgery and may constitute a link in evolution of natural orifice transluminal surgery techniques. Per oral extraction is an attractive technique, but because of its limitations it fails to provide the expected benefits. Having that in mind, one should hardly expect a sudden upsurge in the popularity of POSE. It seems that this technique may become popular only in the centers specializing in minimally invasive surgery and it is unlikely to be common in everyday practice of smaller, non-clinical wards.

7. Winslow E.R., Fleshman J.W., Birnbaum E.H., Brunt L.M.: Wound complications of laparoscopic vs open colectomy. Surg. Endosc. 2002 Oct.; 16 (10): 1420-1425. Epub 2002 Jun. 27.

8. Kalloo A.N., Singh V.K., Jagannath S.B., Niiyama H., Hill S.L., Vaughn C.A., Magee C.A., Kantsevoy S.V.: Flexible transgastric peritoneoscopy: a novel approach to diagnostic and therapeutic interventions in the peritoneal cavity. Gastrointest. Endosc. 2004 Jul.60 (1): 114-117.

9. Sodergren M.H., Markar S., Pucher P.H., Badran I.A., Jiao L.R., Darzi A.: Safety of transvaginal hybrid NOTES cholecystectomy: a systematic review and meta-analysis. Surg. Endosc. 2015 Aug.; 29 (8): 2077-2090.

10. Mazur M.T, Clark H.B.: Gastric stromal tumors. Reappraisal of histogenesis. Am .J. Surg. Pathol. 1983. 7 (6): 507-519.

11. Sicklick J.K., Lopez N.E.: Optimizing Surgical and Imatinib Therapy for the Treatment of Gastrointestinal Stromal Tumors. J. Gastrointest. Surg. 2013 Jun. 18. [Epub ahead of print]

12. Emilie J.F.: Diagnosis of gastrointestinal stromal tumors: a consensus approach. Bull Acad. Natl. Med. 2012 Apr.-May; 196 (4-5): 835-844.

13. Ma B., Huang X.Z., Gao P., Zhao J.H., Song Y.X., Sun J.X., Chen X.W., Wang Z.N.: Laparoscopic resection with natural orifice specimen extraction ver- 
sus conventional laparoscopy for colorectal disease: a meta-analysis. Int. J. Colorectal. Dis. 2015 Nov.; 30 (11): 1479-1488.

14. Huscher C.G., Mingoli A., Sgarzini G., Mogini V.: Transoral extraction of a laparoscopical lyresected large gastric GIST. J. Laparoendosc. Adv.
Surg. Tech. A. 2013 Aug.;23 (8): 707-709.

15. Dotai T., Coker A.M., Antozzi L., Acosta G., Michelotti M., Bildzukewicz N., Sandler B.J., Jacobsen G.R., Talamini M.A., Horgan S.: Transgastric large-organ extraction: the initial human experience. Surg. Endosc. 2013 Feb.; 27 (2):394-399.

\begin{tabular}{|c|c|c|c|c|}
\hline Word count: 2200 & Page count: 5 & Tables: 2 & Figures: - & References: 15 \\
\hline \multicolumn{5}{|c|}{$10.5604 / 01.3001 .0009 .6001$} \\
\hline \multicolumn{5}{|c|}{ http://ppch.pl/resources/html/articlesList?issueld=9609 } \\
\hline
\end{tabular}

Competing interests: The authors declare that they have no competing interests.

2 The content of the journal "Polish Journal of Surgery” is circulated on the basis

- of the Open Access which means free and limitless access to scientific data.

(c) (i) (2) This material is available under the Creative Commons - Attribution 4.0 GB. The full terms of this

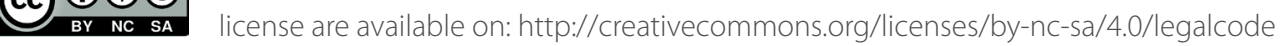

Corresponding author Maciej Stanek, MD, Second Department of General Surgery, Jagiellonian University, Department of Endoscopic, Metabolic and Soft Tissue Tumor Surgery, Kopernika 21, 31-501 Kraków, Poland (tel: +48 698150 053; facsimile: +48 12421 34 56; email: maciej.m.stanek@gmail.com)

Cite this article as: Stanek M., Major P., Wierdak M., Pędziwiatr M., Radkowiak D., Zychowicz A., Budzyński A.; Laparoskopowe resekcje żołądka z usunięciem preparatu przez usta w leczeniu guzów śródściennych żołądka; Pol Przegl Chir 2017: 89 (1): 16-21 
